\title{
Fragile X Mental Retardation Protein Is Required for Rapid Experience-Dependent Regulation of the Potassium Channel Kv3.1b
}

\author{
John G. Strumbos, ${ }^{1}$ Maile R. Brown, ${ }^{1}$ Jack Kronengold, ${ }^{1}$ Daniel B. Polley, ${ }^{2}$ and Leonard K. Kaczmarek ${ }^{1}$ \\ ${ }^{1}$ Department of Pharmacology, Yale University School of Medicine, New Haven, Connecticut 06511, and 2Eaton-Peabody Laboratory, Massachusetts \\ Eye and Ear Infirmary, Boston, Massachusetts 02114
}

\begin{abstract}
Fragile X mental retardation protein (FMRP) is an RNA-binding protein that regulates synaptic plasticity by repressing translation of specific mRNAs. We found that FMRP binds mRNA encoding the voltage-gated potassium channel Kv3.1b in brainstem synaptosomes. To explore the regulation of Kv3.1b by FMRP, we investigated Kv3.1b immunoreactivity and potassium currents in the auditory brainstem sound localization circuit of male mice. The unique features of this circuit allowed us to control neuronal activity in vivo by exposing animals to high-frequency, amplitude-modulated stimuli, which elicit predictable and stereotyped patterns of input to the anterior ventral cochlear nucleus (AVCN) and medial nucleus of the trapezoid body (MNTB). In wild-type (WT) animals, Kv3.1b is expressed along a tonotopic gradient in the MNTB, with highest levels in neurons at the medial, high-frequency end. At baseline, $F m r 1^{-l-}$ mice, which lack FMRP, displayed dramatically flattened tonotopicity in Kv3.1b immunoreactivity and $\mathrm{K}^{+}$currents relative to WT controls. Moreover, after $30 \mathrm{~min}$ of acoustic stimulation, levels of Kv3.1b immunoreactivity were significantly elevated in both the MNTB and AVCN of WT, but not Fmr1 ${ }^{-1-}$, mice. These results suggest that FMRP is necessary for maintenance of the gradient in Kv3.1b protein levels across the tonotopic axis of the MNTB, and are consistent with a role for FMRP as a repressor of protein translation. Using numerical simulations, we demonstrate that Kv3.1b tonotopicity may be required for accurate encoding of stimulus features such as modulation rate, and that disruption of this gradient, as occurs in $F m r 1^{-1-}$ animals, degrades processing of this information.
\end{abstract}

\section{Introduction}

Fragile X syndrome (FXS) is a sex-linked genetic disorder characterized by mild-to-severe intellectual disability, attention deficit, extreme sensitivity to sensory stimuli, and seizures. The disorder is typically caused by a trinucleotide repeat expansion that silences transcription of the X-linked gene Fmr1, which encodes the RNA-binding fragile $\mathrm{X}$ mental retardation protein (FMRP). FMRP acts as a negative regulator of protein synthesis in neurons by binding to target mRNAs and suppressing their translation in an activity-dependent fashion (Bassell and Warren, 2008). One of the first mRNAs to be identified as a candidate binding partner for FMRP encodes Kv3.1, a voltage-gated potassium channel subunit expressed in fast-spiking neurons throughout the brain (Darnell et al., 2001). Kv3.1 channels produce a fast delayed rectifier current that permits neurons to fire prolonged trains of action potentials at very high frequencies with little adaptation (Gan and Kaczmarek, 1998; Rudy and McBain, 2001). Native neurons expressing large amounts of the channel subunit are capable of sustaining high-frequency firing at rates exceeding

Received March 4, 2010; revised June 9, 2010; accepted June 19, 2010.

This work was supported by a FRAXA Research Foundation grant (to L.K.K.) as well as National Institutes of Health Grants DC001919 (to L.K.K.) and DC009488 (to D.B.P.). We thank Kenton Hokanson for technical assistance with Western blots.

Correspondence should be addressed to Leonard K. Kaczmarek, Department of Pharmacology, Yale University School of Medicine, 333 Cedar Street, SHM Room B-309, New Haven, CT 06511. E-mail: leonard.kaczmarek@yale.edu.

DOI:10.1523/JNEUROSCI.1125-10.2010

Copyright $\odot 2010$ the authors $\quad 0270-6474 / 10 / 3010263-09 \$ 15.00 / 0$
$300 \mathrm{~Hz}$, whereas removal of the Kv3.1 current via genetic ablation or pharmacological blockade results in action potential failure in response to the same pattern of stimulation (Wang et al., 1998b; Macica et al., 2003). Conversely, introduction of the Kv3.1 gene into neurons that lack native Kv3.1 expression has been shown to confer a fast-spiking phenotype on cells that normally fire only at low frequencies (Whim and Kaczmarek, 1998). Therefore, altered regulation of Kv3.1 protein translation in the absence of FMRP would be expected to interfere significantly with patterns of neuronal activity in regions where the subunit is expressed.

One region in which the maintenance of appropriate levels of Kv3.1 current is of critical importance is the mammalian binaural sound localization circuit, which relies upon the detection of minute interaural differences in the timing and intensity of sound (Kaczmarek et al., 2005). The globular bushy cells of the anterior ventral cochlear nucleus (AVCN) and their synaptic targets, the principal neurons of the medial nucleus of the trapezoid body (MNTB), participate in this circuit by phase-locking their action potentials to temporal modulations in the acoustic waveform (Joris and Yin, 1998; Kadner and Berrebi, 2008; KoppScheinpflug et al., 2008). In both the AVCN and MNTB, Kv3.1b (the adult splice isoform of Kv3.1) is highly concentrated in presynaptic terminals and in spine-like structures immediately adjacent to postsynaptic membranes, where it permits the faithful transmission of high-frequency synaptic input at rates exceeding $600 \mathrm{~Hz}$ (Wang and Kaczmarek, 1998; Wang et al., 1998a; 
Taschenberger and von Gersdorff, 2000; Elezgarai et al., 2003; Ishikawa et al., 2003; Kaczmarek et al., 2005).

Recently, we have shown that the distribution of $\mathrm{Kv} 3.1 \mathrm{~b}$ across the tonotopic axis of the MNTB can become rapidly and specifically modulated after brief periods of acoustic stimulation (Strumbos et al., 2010). Here, we report that both the baseline $\mathrm{Kv} 3.1 \mathrm{~b}$ tonotopic distribution and its modification by brief sound stimulation are disrupted in $\mathrm{Fmrl}^{-1-}$ mice, indicating that FMRP is required for rapid experiencedependent regulation of Kv3.1b levels. We present a model of MNTB function demonstrating that FMRP-dependent channel gradients may be required for accurate encoding of sound by neuronal ensembles.

\section{Materials and Methods}

Detection of $m R N A$ in FMRP complexes. All experimental protocols involving animals were approved by the Yale University Animal Use and Care Committee. The mice, including the wild-type (WT) (FVB.129P2$\left.\mathrm{Pde}^{+} \mathrm{b}^{+} \mathrm{Tyr}^{\mathrm{c}^{-c h}} / \mathrm{Ant}\right)$ and $\mathrm{Fmrl}^{-1-}$ (FVB.129P2-Fmr1 $\left.{ }^{\mathrm{tm} 1 \mathrm{Cgr}} / \mathrm{J}\right)$ mice, were purchased from Jackson Laboratories. Synaptosomes were isolated and solubilized as previously described (Brown et al., 2006) from pooled brainstem and olfactory bulb brain regions from 2-month-old WT or $\mathrm{Fmrl}^{-/-}$male mice. All protein concentrations were determined using the Quant-it Protein Assay Kit (Invitrogen), and portions of each sample were reserved at this stage and labeled as input samples. For FMRP immunoprecipitations, mouse synaptosome samples were precleared and incubated overnight at $4^{\circ} \mathrm{C}$ with $10 \mu \mathrm{g}$ of mouse anti-FMRP 7G1-1 or 10 $\mu \mathrm{g}$ of anti-mouse IgG antibodies. The monoclonal antibody 7G1-1 developed by Stephen T. Warren (Emory University, Atlanta, GA) was obtained from the Developmental Studies Hybridoma Bank (University of Iowa, Iowa City, IA). Prepared protein A/G beads (Thermo Fisher Scientific) were added to samples and rotated for $2 \mathrm{~h}$ at $4^{\circ} \mathrm{C}$. The beads were washed stringently six times in a wash buffer containing $450 \mathrm{~mm}$ $\mathrm{NaCl}, 5$ mм $\mathrm{MgCl}_{2}, 10$ mм HEPES-KOH, pH 7.4, 0.5 mм DTT, $40 \mathrm{U} / \mathrm{ml}$ protector RNase inhibitor (Hoffmann-La Roche) and $1 \times$ complete EDTA-free protease inhibitor mixture tablet followed by centrifugation (Stefani et al., 2004; Iacoangeli et al., 2008). The agarose beads containing protein-RNA complexes were incubated in $120 \mu \mathrm{g}$ of Proteinase K (Hoffmann-La Roche) at $37^{\circ} \mathrm{C}$ for $15 \mathrm{~min}$. RNA was extracted using the RNeasy Mini Kit (Qiagen). RNA was used to prepare cDNA using random primers and the High Capacity cDNA Reverse Transcription Kit (Applied Biosystems). Five microliters of first-strand cDNA was used with Platinum HiFi Taq (Invitrogen) in a total volume of $50 \mu$ l. The PCR was conducted as follows: 38 cycles at $94^{\circ} \mathrm{C}$ for $30 \mathrm{~s} ; 60^{\circ} \mathrm{C}$ for $30 \mathrm{~s} ; 68^{\circ} \mathrm{C}$ for $1 \mathrm{~min}$; followed by 1 cycle at $72^{\circ} \mathrm{C}$ for $5 \mathrm{~min}$. Primers were designed to amplify a 464 bp product targeting the $5^{\prime}$ coding region of the $K v 3.1$ gene: Kv3.1 forward primer GTGCCGACGAGTTCTTCTTC and reverse primer TGTGATGGAGACCAGGATGA. Map1b, a known mRNA target of FMRP, primers were used as a positive control in a separate PCR designed to amplify a 450 bp product: Map1b forward primer GGCAAGATGGGGTATAGAGA; Map $1 b$ reverse primer CCCACCTGCTTTGGTCTTTG. PCR products were run out on a $2 \%$ agarose gel and imaged using an Epi Chemi II (UVP Laboratory Products).

Western blotting. Brainstem-enriched homogenate samples were separated by SDS-PAGE followed by electrophoretically transferring the polypeptides to membranes. Membranes were incubated at room temperature for $1 \mathrm{~h}$ in either 20\% BlokHenII (Aves Labs) or 5\% nonfat milk in $50 \mathrm{~mm}$ Tris-saline containing $0.05 \%$ Tween-20 at pH 7.5 (TTBS). The blots were incubated overnight in either mouse anti-Kv3.1b (NeuroMab) or mouse anti-GAPDH (Santa Cruz Biotechnology). After overnight incubation in primary antibody, membranes, were washed in TTBS and incubated in secondary antibody for $1 \mathrm{~h}$ in HRP-conjugated goat anti-mouse IgG. The blots were rinsed thoroughly, developed using Pierce SuperSignal West Pico chemiluminescent substrate, exposed to Kodak T-MAX film, and developed using the Konica Medical Film Processor.

Acoustic stimulation. Thirteen WT and $12 \mathrm{Fmrl}^{-1-}$ awake adult male mice (4-5 months old) were exposed to amplitude-modulated (AM) stimuli for a $30 \mathrm{~min}$ period at a $65 \mathrm{~dB}$ sound pressure level in a small sound-attenuating chamber. Stimuli consisted of $32 \mathrm{kHz}$ pure tones modulated at either intermediate rates $(57-63 \mathrm{~Hz})$ or high rates $(380-$ $420 \mathrm{~Hz}$ ). Control mice from both genotypes ( $5 \mathrm{WT}$ mice and $4 \mathrm{Fmrl}^{-1-}$ mice) were placed in the sound-attenuating chamber for $30 \mathrm{~min}$ before being killed but did not receive stimulation. Sound-stimulated WT and Fmr1 $1^{-1-}$ mice were randomly separated into the following two groups: group 1 received intermediate-rate $\mathrm{AM}$ stimulation $(n=8)$; and group 2 received high-rate AM stimulation $(n=8)$. After densitometric analyses of Kv3.1b immunoreactivity in the MNTB and AVCN, no significant differences were observed between mice receiving the two different sound-stimulation protocols, and groups were subsequently combined for statistical comparisons. At the final minute of acoustic exposure, mice were anesthetized by open-drop inhalation of $30 \%$ isoflurane/propylene glycol mixture (Medical Developments International) and quickly and silently killed with a lethal dose of pentobarbital sodium followed by transcardial perfusion with $0.1 \mathrm{M}$ PBS followed by fixative (4\% paraformaldehyde in $0.1 \mathrm{M}$ phosphate buffer, $\mathrm{pH}$ 7.4). After fixation for $24 \mathrm{~h}$ at $4^{\circ} \mathrm{C}$, brainstem sections were transferred to $0.1 \mathrm{M}$ PBS for storage.

Immunohistochemistry. All 25 brains used in this study were embedded into a single gelatin block to permit simultaneous sectioning and immunohistochemical staining (MultiBrain technology, NSALabs). The gelatin block containing 25 brains was frozen, and serial coronal sections ( 35 $\mu \mathrm{m}$ thick) were collected from bregma -4.6 to -6.4 . Every third section, at $105 \mu \mathrm{m}$ intervals, was DAB immunolabeled for Kv3.1b using a rabbit polyclonal antibody directed at the cytoplasmic $\mathrm{C}$ terminus of the channel (Alomone Labs).

Densitometry. Quantification of the tonotopic gradient was performed using a variation of methods described previously (Li et al., 2001a; von Hehn et al., 2004). Briefly, images were converted to 8 bit images and digitally thresholded for cell identification. Cells were outlined using the ImageJ particle analysis algorithm (minimum area, 200 pixels), and regions above the threshold were carefully examined to exclude artifacts. After cell identification, images were divided into five equal zones, and cells were sorted according to their location along the azimuth. In some cases, contiguous regions of immunoreactivity represented more than one cell. To control for differences in the size and density of Kv3.1blabeled cells between zones, the integrated optical density (total sum of gray values for all pixels) in each zone was divided by the total pixelsabove-threshold in that zone. No distinction was made between internal and plasma membrane immunoreactivity, nor was it possible to distinguish between presynaptic and postsynaptic immunoreactivity. Three- 
a WT Low-freq $\rightarrow$ High-freq

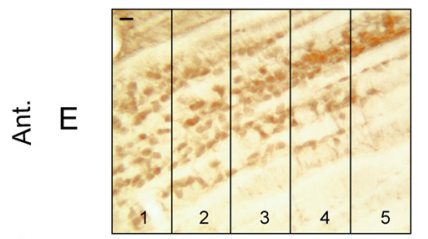

D

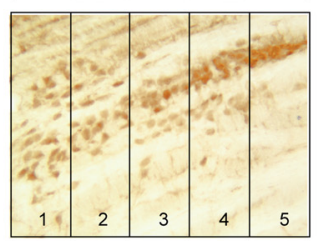

C

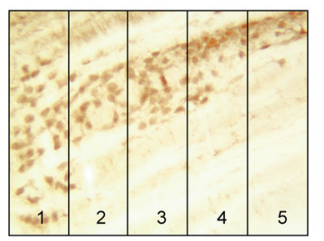

B

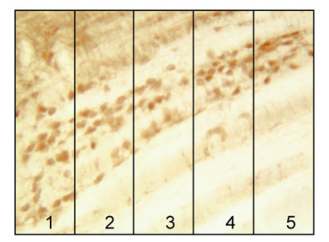

茂

A

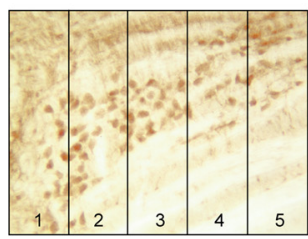

Lat
$\mathrm{Fmr1}^{-/-}$

b
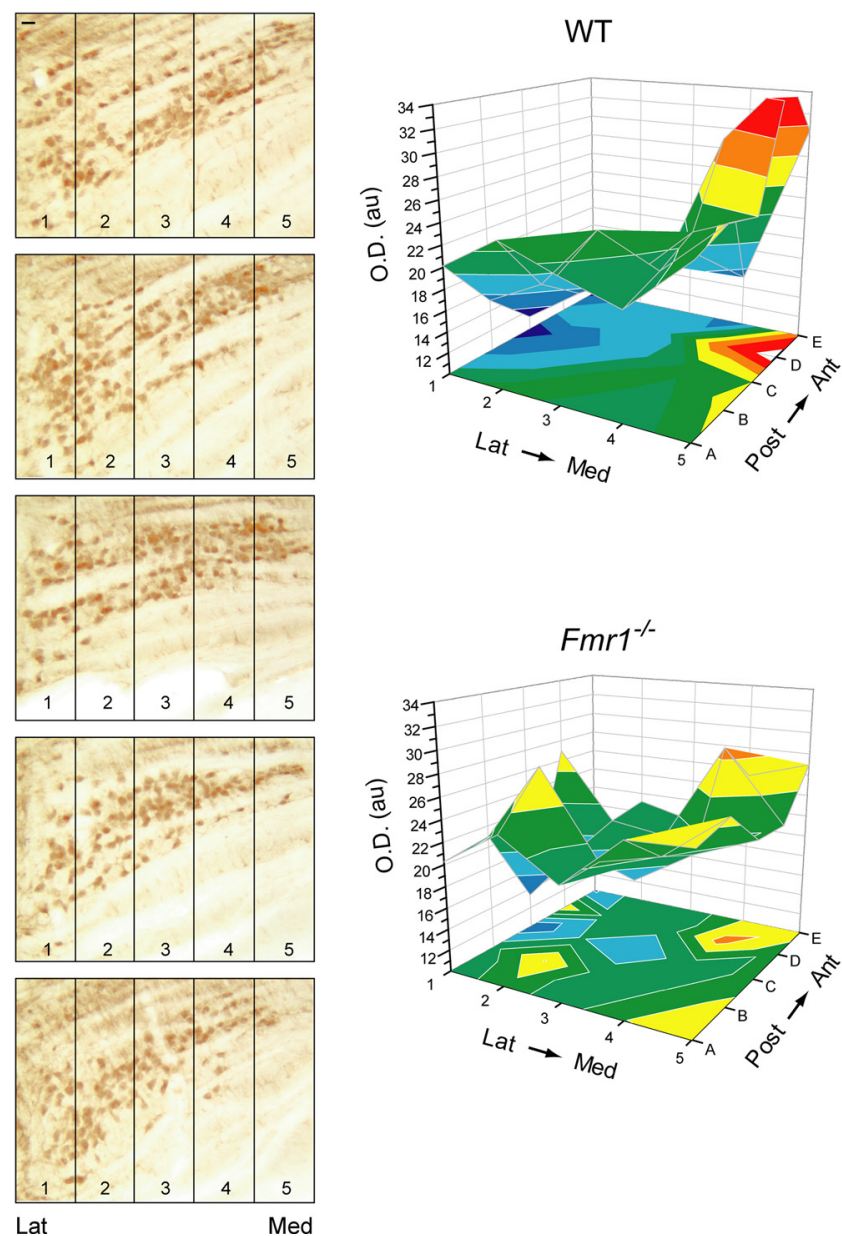

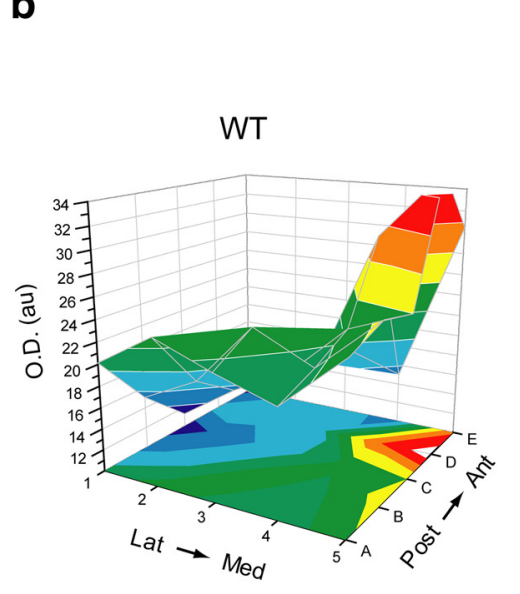

$\square$ $>34$
31
28
25
22
19
16
13
10
$<10$
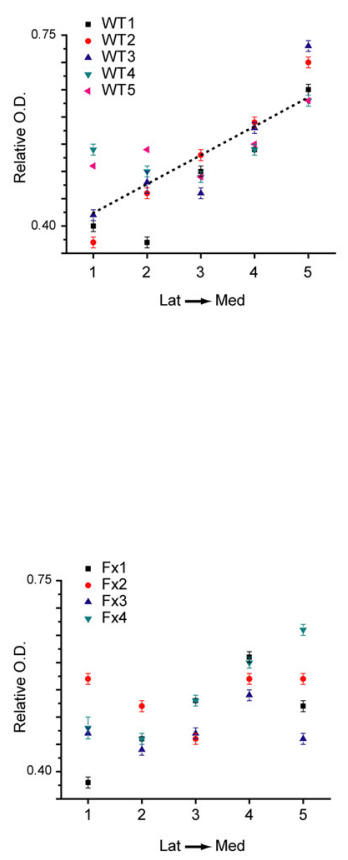

Figure 2. Kv3.1b tonotopicity is flattened in Fmr $1^{-1-}$ mice. $\boldsymbol{a}$, Representative MNTB sections from a single WT and Fmr $1^{-1-}$ mouse demonstrating the flattened pattern of Kv3.1b immunoreactivity across the rostrocaudal and mediolateral axes of the MNTB. Scale bar, $20 \mu \mathrm{m}$. $\boldsymbol{b}$, Representative three-dimensional plots of average Kv3.1b immunoreactivity (0D) in each of 25 stereotaxic zones. Plots correspond to the sections shown on left. Insets, Plots of relative OD across the mediolateral axis for each control animal used in the study $(n=9)$. Data points represent the average and SE of 5 sections for each animal. To facilitate comparisons across animals, the OD in each section was normalized to the darkest cell in the section. A linear regression for the WT plots was statistically significant ( $p=0.01, R^{2}=0.86$; dotted line), whereas a linear regression for the gradient in Fmr ${ }^{-1-}$ mice was not statistically significant $\left(p=0.08, R^{2}=0.83\right)$. Lat, Lateral; Med, medial; Post, posterior; Ant, anterior; freq, frequency.

dimensional plots representing relative $\mathrm{Kv} 3.1 \mathrm{~b}$ immunoreactivity across both the coronal and sagittal planes were constructed by dividing five consecutive sections into five equal zones across the mediolateral axis, yielding a total of 25 zones per animal. Three-dimensional curve-fits were obtained using the thin-plate spline algorithm (smoothing factor $=$ $1.0,5 \times 5$ grid, OriginPro 8).

Electrophysiological recordings. Brainstem slices from postnatal WT or Fmr1 ${ }^{-1-}$ male mice aged 9-14 d [postnatal day (P) 9-P14] were prepared as described previously (Barnes-Davies and Forsythe, 1995). Briefly, mice were decapitated, and the brainstem was removed into iced low- $\mathrm{Na}^{+}$, high-sucrose artificial CSF (ACSF) containing the following (in mM): 250 sucrose, $2.5 \mathrm{KCl}, 26 \mathrm{NaHCO}_{3}, 1.25 \mathrm{NaH}_{2} \mathrm{PO}_{4}, 2$ sodium pyruvate, 3 myo-inositol, 10 glucose, $0.5 \mathrm{CaCl}_{2}$, and $3.5 \mathrm{MgCl}_{2}$; saturated with $95 \% \mathrm{O}_{2}-5 \% \mathrm{CO}_{2}$, giving a $\mathrm{pH}$ of 7.4. The brainstem was glued to a Vibratome stage (Lancer Series 1000, Technical Products International), and the area containing MNTB nuclei was cut into four to six transverse slices. Slices $\left(250 \mu \mathrm{m}\right.$ thick) were incubated for $1 \mathrm{~h}$ at $37^{\circ} \mathrm{C}$ in normal ACSF containing the following (in mM): $125 \mathrm{NaCl}, 2.5 \mathrm{KCl}, 26 \mathrm{NaHCO}_{3}$, 10 glucose, $1.25 \mathrm{NaH}_{2} \mathrm{PO}_{4}, 2 \mathrm{CaCl}_{2}, 1 \mathrm{MgCl}_{2}, 3$ myo-inositol, 2 sodium pyruvate; and bubbled with $95 \% \mathrm{O}_{2}-5 \% \mathrm{CO}_{2}, \mathrm{pH} 74$. Whole-cell recordings were made from visually identified MNTB principal neurons using an EPC-7 amplifier (HEKA Elektronik). All recordings were performed at room temperature $\left(21-22^{\circ} \mathrm{C}\right)$. Electrodes for whole-cell recordings had a resistance of 3-5 $\mathrm{M} \Omega$ when filled with an intracellular solution containing the following (in $\mathrm{mm}$ ): 117.5 potassium gluconate, $12.5 \mathrm{KCl}, 5$ EGTA, $10 \mathrm{HEPES}, 1 \mathrm{MgCl}_{2}$, and $20 \mathrm{NaCl}, \mathrm{pH}$ 7.2. The series resistance for whole-cell recordings from MNTB neurons was $<12 \mathrm{M} \Omega$ and compensated at least $85 \%$. No corrections were made for liquid-junction potentials. Data were filtered at $5 \mathrm{kHz}$ and sampled at $10 \mathrm{kHz}$.

Numerical simulations. Responses for model MNTB neurons with varying levels of Kv3.1 current were computed exactly as described previously, using the same numerical parameters (Song et al., 2005). The phase vector strength that relates the timing of action potentials to that of stimulus pulses was also calculated for individual neurons as described previously (Song et al., 2005; Yang et al., 2007). To assess the accuracy of timing of the output of multiple neurons in a linear ensemble of neurons in which Kv3.1 current levels were progressively increased along a gradient, we calculated an adjusted phase vector strength. We first combined the spike outputs of 2-30 neighboring neurons along the gradient. The timing of response to each pulse was then fixed to be the timing of the earliest latency spike in group output, and the phase vector strength was then calculated for this combined output exactly as for a single neuron. This vector strength was then multiplied by the fraction of stimulus pulses that evoked at least one action potential to generate the final 
adjusted phase vector strength. This adjusted vector strength has the property that, in an ensemble of neurons, even if every evoked action potential has exactly the same latency with respect to the stimulus pulses, a vector strength of 1.0 can only be achieved if every stimulus evokes an action potential in at least one neuron of the ensemble.

\section{Results}

\section{FMRP binds $K v 3.1 b$ mRNA in brainstem-enriched} synaptosomes

$K v 3.1 b$ mRNA contains the canonical G-quartet sequence predicted to specify binding of a target mRNA to FMRP (Darnell et al., 2001). To confirm the in vivo interaction of FMRP and $K v 3.1 b$, we performed RT-PCR experiments on FMRP immunoprecipitates from brainstem-enriched synaptosomes isolated from WT and Fmr1 ${ }^{-1-}$ mice (see Materials and Methods). After isolation of RNA and RT-PCR with primers designed to detect the $5^{\prime}$ region of $K v 3.1 b$ mRNA, we detected $K v 3.1 b$ mRNA in FMRP immunoprecipitates from WT mice (Fig. $1 a$, lane 3 ). As a positive control, we also used a set of primers to detect Map1b, a known FMRP target mRNA, in FMRP immunoprecipitates from WT mice (Fig. 1a, lane 7). As negative controls, no $K v 3.1 b$ or Map $1 b$ mRNA was detected in FMRP immunoprecipitates from synaptosomes prepared from $F m r 1^{-1-}$ mice (Fig. 1a, lanes 4, 8). Total levels of Kv3.1b protein in brainstem-enriched homogenates were not significantly different in WT versus $\mathrm{Fmrl}^{- \text {- }}$ mice, suggesting that FMRP-dependent regulation of Kv3.1b translation is restricted to specific pools of $K v 3.1 b$ mRNA that may only account for a small proportion of total brainstem Kv3.1b (Fig. $1 b)(n=5, p=0.78)$.

\section{$\mathrm{Kv} 3.1 \mathrm{~b}$ tonotopicity is flattened in $\mathrm{Fmrl}^{-/-}$mice}

The principal cells of the MNTB are organized tonotopically, such that lateral cells respond preferentially to low carrier frequencies and medial cells respond best to high carrier frequencies (Guinan et al., 1972; Sommer et al., 1993; Ehret and Romand, 1997). In WT animals, Kv3.1b protein levels and current amplitudes vary systematically across the tonotopic axis of the MNTB, with the highest levels of the channel in the medial, highfrequency end (Li et al., 2001a; Brew and Forsythe, 2005). In deaf mice, this orderly topographic distribution of $\mathrm{Kv} 3.1 \mathrm{~b}$ becomes abolished, indicating that sensory-dependent patterns of afferent synaptic input are required for maintenance of the gradient (von Hehn et al., 2004; Leao et al., 2006).

To investigate the role of FMRP in regulating Kv3.1b translation, we analyzed the distribution of Kv3.1b immunoreactivity in the MNTB of WT and Fmr1 ${ }^{-1-}$ mice using densitometry $(n=9)$. Serial sections ( $35 \mu \mathrm{m}$ thick) were collected and immunolabeled using a rabbit polyclonal anti-Kv3.1b antibody directed at the cytoplasmic C terminus of the channel. We quantified the pattern of Kv3.1b immunoreactivity throughout the entire MNTB by analyzing every third coronal section across the entire rostrocaudal extent of the nucleus. To facilitate comparisons, threedimensional (3D) optical density (OD) plots were constructed by dividing five consecutive sections into five equal zones across the mediolateral axis, yielding a total of 25 zones per animal (Fig. $2 a, b)(n=9)$. Relative to WT mice, the tonotopic gradient of Kv3.1b protein was substantially flattened in Fmr1 ${ }^{-1-}$ animals, such that Kv3.1b levels were more uniform throughout the MNTB. Whereas the mediolateral gradient in Kv3.1b immunoreactivity was significantly linear in WT mice (Fig. $2 b)\left(p=0.01, R^{2}=0.86\right)$, a linear regression for the gradient in $F m r 1^{-1-}$ mice was not statistically significant (Fig. 2b) $\left(p=0.08, R^{2}=0.83\right)$.

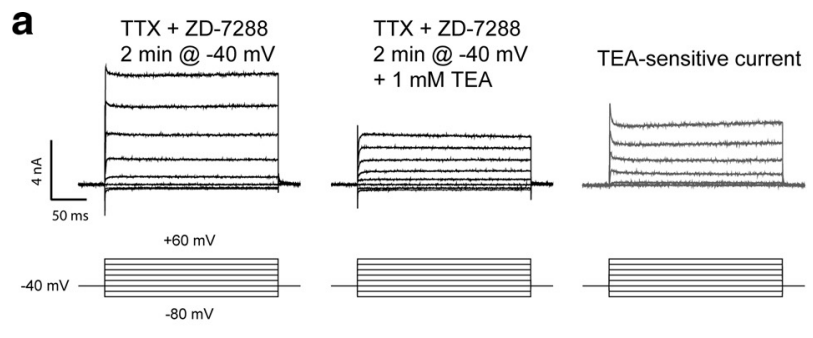

b

WT
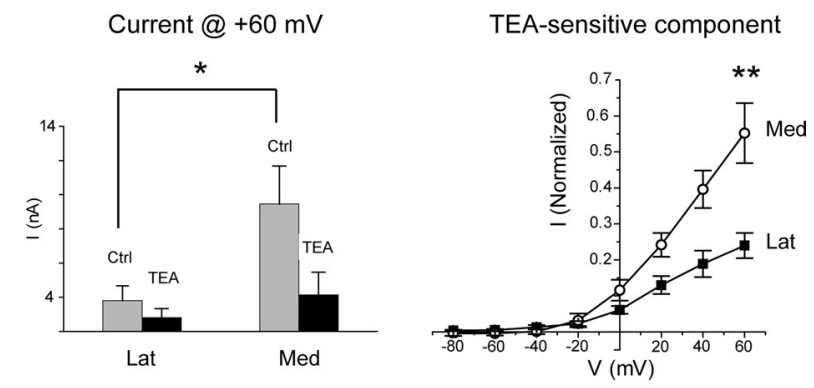

c

$F m r^{-/}$

Current @+60 mV
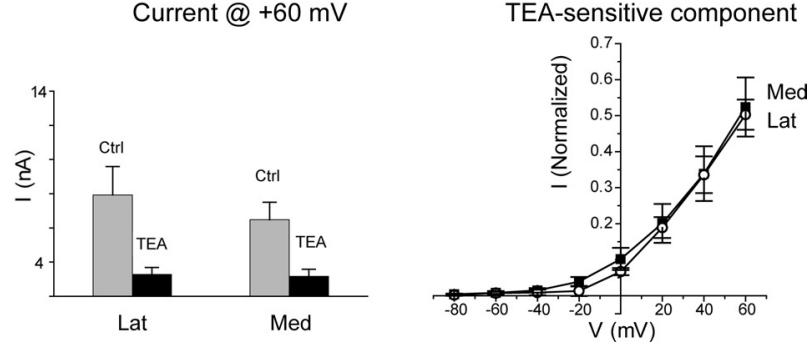

Figure 3. Kv3.1-like currents do not vary between lateral and medial MNTB neurons in $\mathrm{Fmr1}^{-1-}$ mice. $\boldsymbol{a}$, Representative traces demonstrating the technique for isolating the Kv3.1like current in MNTB neurons, which mainly represents the activity of Kv3.1b homomers (Wang et al., 1998b; Macica et al., 2003). Control traces are recorded in the presence of TTX (1 $\mu \mathrm{M})$ and ZD-7288 $(20 \mu \mathrm{m})$ to block $\mathrm{Na}^{+}$and $h$-currents, respectively. Cells were held at a resting potential of $-40 \mathrm{mV}$ for at least $2 \mathrm{~min}$ before all recordings to ensure complete inactivation of low-threshold, voltage-activated $\mathrm{K}^{+}$currents (left). Application of $1 \mathrm{~mm}$ TEA selectively blocks the high-threshold Kv3.1-like current (center). The TEA-sensitive current is shown in gray (right). A schematic of the pulse protocol is shown below traces. $\boldsymbol{b}, \boldsymbol{c}$, Consistent with our densitometric analysis, the proportion of $\mathrm{K}^{+}$current that was blocked by $1 \mathrm{~mm}$ TEA when neurons were stepped from -40 to $+60 \mathrm{mV}$ varied significantly $\left.{ }^{* *}\right)$ between medially and laterally located neurons in WT mice ( $\boldsymbol{b}$, right; $n=8, p=0.009$, unpaired $t$ test), but not in Fmr ${ }^{-1-}$ mice (c, right; $n=8, p=0.84$, unpaired $t$ test). The amplitude of total $\mathrm{K}^{+}$current at $+60 \mathrm{mV}$ also differed significantly $\left({ }^{*}\right)$ across the tonotopic axis in WT mice (b, left; $n=8$, $p=0.03$, unpaired $t$ test), but not in $F m r 1^{-1-}$ mice (c, left; $n=8, p=0.56$, unpaired $t$ test). Lat, Lateral; Med, medial.

During a short developmental window after the onset of hearing in mice (P9-P14), MNTB principal cells are accessible to patch-clamp recording from acutely prepared slices (Wang et al., 1998b). To test the physiological impact of reduced Kv3.1b tonotopicity, we performed patch-clamp recordings from visually identified MNTB principal cells in juvenile (P9-P14) WT and Fmr1 ${ }^{-1-}$ mice (Fig. 3). The Kv3.1-like current was isolated by holding cells at a potential of $-40 \mathrm{mV}$ for $2 \mathrm{~min}$ to ensure inactivation of low-threshold currents and then measuring the component of current that was eliminated by a low concentration ( 1 $\mathrm{mm}$ ) of tetraethylammonium (TEA), which selectively blocks Kv3.1b in these cells (Kanemasa et al., 1995; Wang et al., 1998b). Previous work has shown that this current is likely carried by 


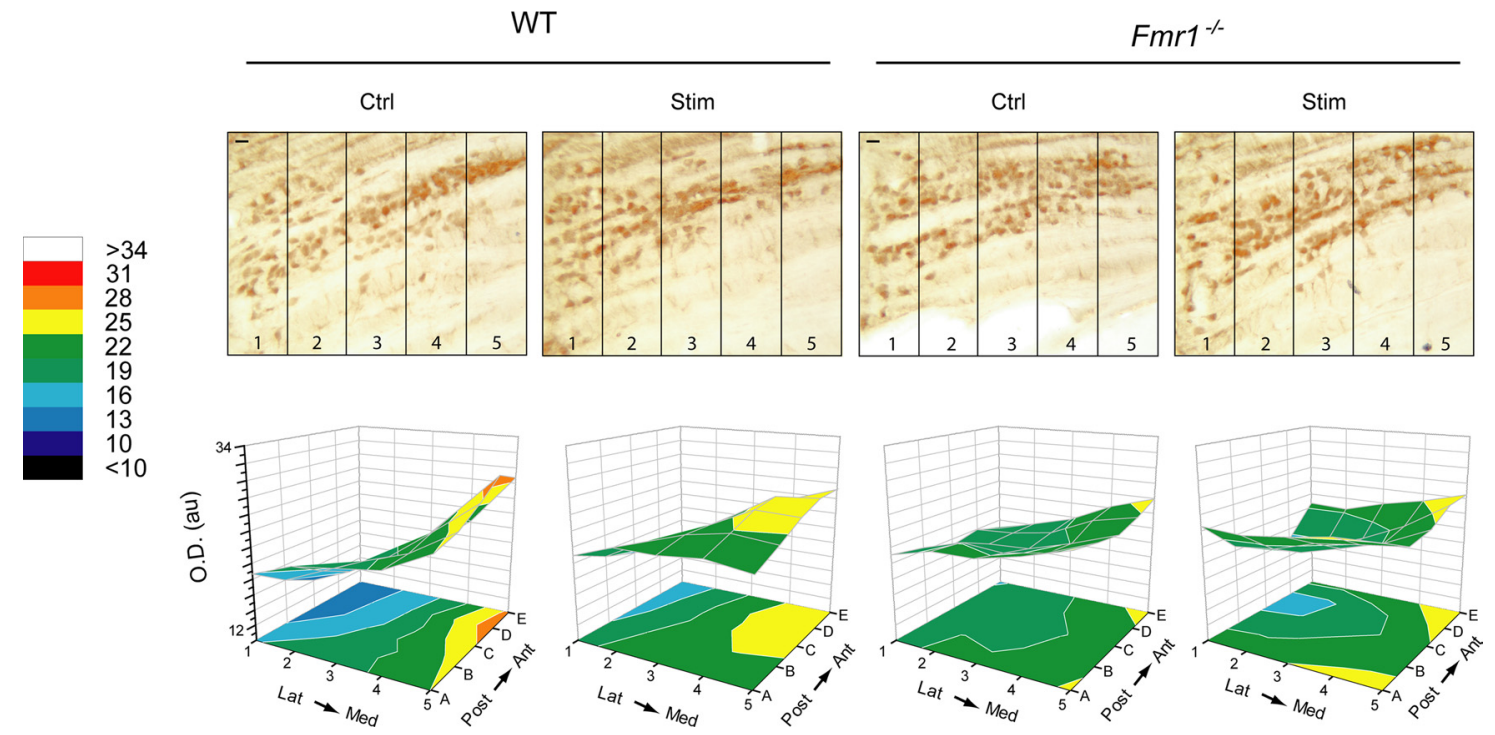

Figure 4. Representative sections and 3D tonotopic curve-fits. All sections shown were immunolabeled simultaneously on the same slide (above). The WT and $F m r 1^{-1-}$ control sections are from the same animals shown in Figure 2. Representative three-dimensional curve-fits (below) are shown to highlight the flattening of the tonotopic gradient after 30 min high-frequency acoustic stimulation in WT, but not $\mathrm{Fmr}^{-I-}$, mice. Curves were constructed from raw data (e.g., those shown in Fig. 2) using a thin-plate spline algorithm. Lat, Lateral; Med, medial; Post, posterior; Ant, anterior.
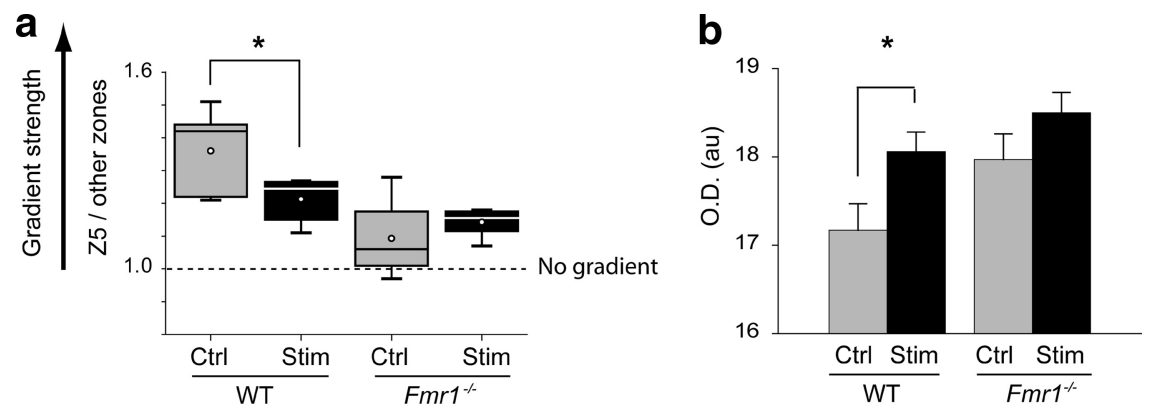

Figure 5. Rapid effects of acoustic stimulation on Kv3.1b tonotopicity and total levels of Kv3.1b immunoreactivity in the MNTB. $\boldsymbol{a}$, Gradient strength (curvature) was quantified for each animal $(n=25)$ by calculating the ratio of immunoreactivity in zone 5 to the average immunoreactivity in the zones $1-4$ (Z5 ratio). Box plot shows the full range of $Z 5$ ratios from each treatment group. Maximum and minimum (error bars), 99 and 1\% (box), mean (circle), and median (horizontal line) values are shown for each group. We observed a significant difference $\left.{ }^{*}\right)$ in the $Z 5$ ratios between WT control mice and WT mice receiving acoustic stimulation ( $n=13, p=0.02$, unpaired $t$ test). In $F m r 1^{-1-}$ mice, we observed no significant effect of stimulation on the $Z 5$ ratio ( $n=12, p=0.33$, unpaired $t$ test). $\boldsymbol{b}$, Total levels of MNTB Kv3.1b immunoreactivity in each group were determined by measuring the mean $O D$ of each section ( $N=365$ sections). Kv3.1b levels were significantly elevated $(*)$ in sound-stimulated WT mice relative to WT controls $(N=162$ sections, $p=0.02$, unpaired $t$ test). By contrast, sound stimulation did not significantly influence total Kv3.1b levels in $F m r 1^{-1-}$ mice $(N=203$ sections, $p=0.17$, unpaired $t$ test). Ctrl, Control; Stim, stimulated.

homomeric Kv3.1b channels and that it is missing in $K v 3.1^{-1-}$ animals (Macica et al., 2003). Consistent with our densitometric analysis, the proportion of total $\mathrm{K}^{+}$current that was blocked by 1 $\mathrm{mm}$ TEA when neurons were stepped from -40 to $+60 \mathrm{mV}$ varied significantly between medially and laterally located neurons in WT mice, but not in Fmr1 ${ }^{-1-}$ mice (Fig. $3 b, c$ ) (WT mice: $0.55 \pm 0.08$ vs $0.24 \pm 0.03$, respectively; $n=8 ; p=0.009$; Fmr $1^{-1-}$ mice: $0.50 \pm 0.04$ vs $0.52 \pm 0.08$, respectively; $n=8$; $p=0.84$, unpaired $t$ test). The amplitude of total $\mathrm{K}^{+}$current at $+60 \mathrm{mV}$ also differed significantly across the tonotopic axis in WT mice, but not in Fmr1 ${ }^{-1-}$ mice (Fig. 3b,c) (WT mice: $9.45 \pm$ 2.22 vs $3.80 \pm 0.86 \mathrm{nA}$, respectively; $n=8 ; p=0.03 ; \mathrm{Fmrl}^{-1-}$ mice: $6.49 \pm 1.02$ vs $7.93 \pm 1.67 \mathrm{nA}$, respectively; $n=8 ; p=0.56$, unpaired $t$ test).
Acoustic environment regulates $\mathrm{Kv} 3.1 \mathrm{~b}$ levels and tonotopicity in WT, but not Fmr1 ${ }^{-/-}$, mice

In vivo single-unit studies have demonstrated that AVCN bushy cells and MNTB principal neurons synchronize their action potentials to the phase of AM sound stimuli (Joris and Yin, 1998; Kadner and Berrebi, 2008; Kopp-Scheinpflug et al., 2008), making it possible to precisely control their activity patterns in vivo by exposing animals to high-frequency AM sounds. We took advantage of this circuit to test the hypothesis that FMRP regulates Kv3.1b translation in an activitydependent fashion. WT and Fmr1 ${ }^{-1-}$ mice were passively exposed to high-frequency (32 kHz) AM acoustic stimuli for a $30 \mathrm{~min}$ period $(n=16)$. Control WT and $\mathrm{Fmrl}^{-/-}$mice spent $30 \mathrm{~min}$ in the same sound-attenuating chamber but did not receive acoustic stimulation $(n=9)$. After $30 \mathrm{~min}$ of sound stimulation, the tonotopic distribution of Kv3.1b in the MNTB of WT mice was altered. Although the mediolateral gradient was still significantly fit by a linear regression $\left(p=0.01, R^{2}=0.88\right)$ the distribution of immunoreactivity was more evenly distributed across the tonotopic axis (Fig. 4). To more accurately quantify the strength (curvature) of the gradient, we analyzed the ratio of immunoreactivity in the most medial neurons (zone 5) to the average immunoreactivity in the rest of the MNTB (zones 1-4). Using this metric, we observed a significant effect of sound stimulation on the strength of the gradient in WT mice, indicating that Kv3.1b levels became more uniform across the tonotopic axis (Fig. $5 a)(p=0.02$, unpaired $t$ test; $n=$ 13). Consistent with this observation, total levels of Kv3.1b immunoreactivity in both the MNTB (Fig. 5b) and AVCN (Fig. 6c) were significantly elevated in sound-stimulated WT mice relative 
to WT controls (unpaired $t$ test, $p=0.02$, $N=162$ sections and $p=0.02, N=81$, respectively). By contrast, we observed no significant effect of sound stimulation on the strength of the MNTB tonotopic gradient in Fmr1 ${ }^{-1-}$ mice (Fig. 5a) $(p=$ 0.33 , unpaired $t$ test; $n=12$ ), nor on total levels of $\mathrm{Kv} 3.1 \mathrm{~b}$ immunoreactivity in either the MNTB or AVCN (Figs. 5b, 6c) $(p=$ $0.29, N=203$ sections and $p=0.68, N=68$ sections, respectively). In the AVCN, both control and sound-stimulated Fmr1 ${ }^{-1-}$ mice displayed elevated Kv3.1b levels relative to WT controls (Fig. $6 c$ ) (control, $p=0.04$; stimulated, $p=0.04$, ANOVA followed by Tukey test). As a negative control for the effects of sound stimulation, we analyzed Kv3.1b immunoreactivity in the molecular layer of the cerebellum, where dense staining is observed in the granule cell axons of the parallel fiber system (Weiser et al., 1995). In the cerebellum, sound stimulation had no effect on Kv3.1b immunoreactivity in either WT or Fmrl ${ }^{-1-}$ mice (Fig. 7b) ( $p=0.56, N=65$ sections and $p=0.16$, $N=60$ sections, respectively). Together, these results are consistent with a role for FMRP in regulating Kv3.1b protein levels in response to afferent synaptic input.

\section{Physiological consequences of flattened} $\mathrm{Kv} 3.1 \mathrm{~b}$ tonotopicity in $\mathrm{Fmr1}^{-/-}$mice To determine the physiological impact of flattened Kv3.1b tonotopicity in the MNTB, we used a previously developed computer model of MNTB principal cells that incorporates Kv3.1 currents with sodium and low-threshold currents measured experimentally (Wang and Kaczmarek, 1998; Song et al., 2005; Yang et al., 2007). The timing fidelity of action potentials evoked in a single MNTB neuron can be evaluated for different levels of Kv3.1 conductance by calculating a phase vector strength, which relates the timing of stimuli to their evoked action potentials. For stimulus frequencies at which all evoked action potentials have exactly the same latency, the phase vector strength is maximal (1.0), whereas action potentials that have random timing with respect to the stimuli result in a vector strength of zero. At frequencies for which an action potential cannot be generated to every stimulus, MNTB neurons maintain phase-locking by firing precisely on every second or third stimulus (Oertel, 1997; Trussell, 1999; Kopp-Scheinpflug et al., 2003). We have previously demonstrated that increasing the level of Kv3.1 conductance, while maintaining all other ionic conductances constant, permits MNTB neurons to follow higher stimulus rates, albeit with lower temporal accuracy (Macica et al., 2003; Song et al., 2005). We have also shown that, for a given level of Kv3.1 conductance, an MNTB neuron that cannot respond to every stimulus pulse will achieve maximal phaselocking at only a discrete range of stimulation frequencies up to its maximum following frequency (Song et al., 2005).

To assess the function(s) of a gradient in Kv3.1 conductance within a neuronal ensemble, we computed the strength of an

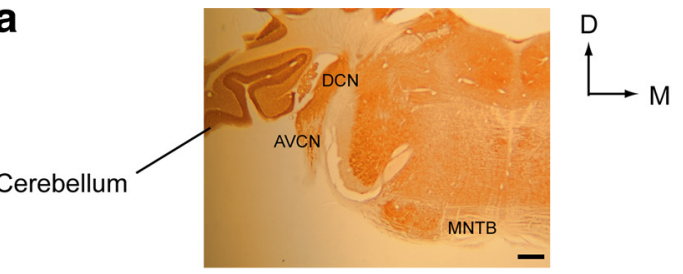

Stim
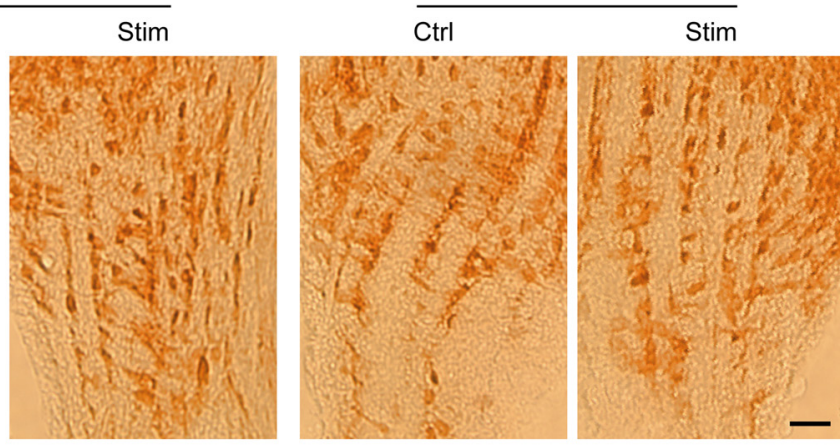

C

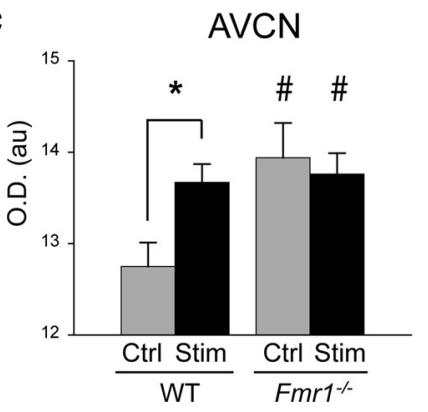

WT

Figure 6. Rapid effects of acoustic stimulation on total levels of Kv3.1b immunoreactivity in the AVCN. $\boldsymbol{a}$, LowScall $200 \mu \mathrm{m} . \boldsymbol{b}, \boldsymbol{c}$, Total levels of AVCN Kv3.1b immunoreactivity in each group were determined by measuring the $p=0.02$, unpaired $t$ test). By contrast, sound stimulation did not significantly influence total Kv3.1b levels in Fmr ${ }^{-1-}$ mice ( $N=68$ sections, $p=0.68$, unpaired $t$ test). Both groups of $F \mathrm{mr}^{-1-}$ mice displayed significantly elevated $\left(^{*}\right)$ Kv3.1b levels relative to WT controls [control (Ctrl), $p=0.04$; stimulated (Stim), $p=0.04$, ANOVA followed by Tukey test].

adjusted phase vector that integrates the combined input from multiple MNTB neurons (Fig. 8a) (see Materials and Methods). Figure $8 b$ illustrates the inherent advantage for sensory processing when a range of Kv3.1 conductances are present across the tonotopic axis. Two sets of 30 neurons are shown, representing either uniform levels of Kv3.1 (left) or a gradient in Kv3.1 levels across the tonotopic axis (right). In the left panels, the level of Kv3.1 conductance is fixed at $0.2 \mu \mathrm{S}$. In the right panels, the neurons vary systematically in their Kv3.1 conductance from $0.02 \mu \mathrm{S}$ to $0.6 \mu \mathrm{S}$. Whereas the 400 and 700 $\mathrm{Hz}$ stimulus each produce an identical pattern of firing in the group of neurons with fixed levels of Kv3.1 conductance, these two stimuli produce very different patterns of activity across the tonotopic axis when a gradient is present. In the presence of a gradient, the integrated phase vector improves as the number of cells contributing to encoding increases, whereas with uniform Kv3.1 levels it remains fixed. Therefore, we conclude that the presence of a gradient in the Kv3.1 conductance (or other channel conductances) may contribute to accurate temporal processing of acoustic stimuli by expanding the range of frequencies that can be encoded. 
a

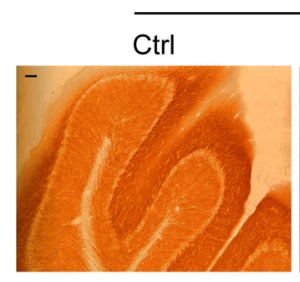

WT

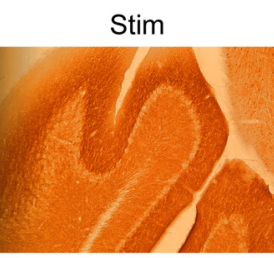

b

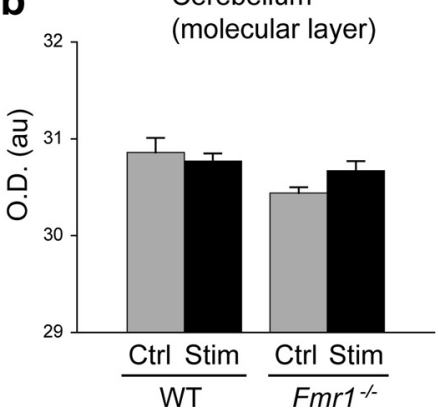

Figure 7. Acoustic stimulation has no effect on total levels of Kv3.1b immunoreactivity in the molecular layer of the cerebellum. $\boldsymbol{a}$, As a negative control for the effects of sound stimulation, we measured Kv3.1b levels in the molecular layer of the cerebellum, where Kv3.1b is highly expressed in the parallel fibers of cerebellar granule cells (Weiser et al., 1995). Scale bar, $40 \mu \mathrm{m} . \boldsymbol{b}$, We observed no effect of sound stimulation on Kv3.1 b levels in WT mice $\left(N=65\right.$ sections, $p=0.56$, unpaired $t$ test) or $F m r 1^{-I-}$ mice $(N=60$ sections, $p=0.16$, unpaired $t$ test). Ctrl, Control; Stim, stimulated.

\section{Discussion}

Although FMRP has been estimated to interact with as many as $4 \%$ of total brain mRNAs (Ashley et al., 1993; Brown et al., 2006), only a small subset $(\sim 12)$ of these mRNAs have been validated experimentally (Bassell and Warren, 2008). Even among FMRP target mRNAs that have been validated, the functional consequences of translational dysregulation are often unclear. In this study, we have validated $K v 3.1$ as a target mRNA for FMRP in vivo and implicated a specific role for this interaction in sensory processing. Although it is known that FMRP can suppress mRNA translation in vitro (Laggerbauer et al., 2001; Li et al., 2001b) and that loss of FMRP results in excess protein synthesis of specific mRNA targets (Zalfa et al., 2003; Lu et al., 2004; Muddashetty et al., 2007), to the best of our knowledge, this is the first study to describe a form of FMRP-dependent sensory plasticity in vivo.

In the rat, the tonotopic distribution of Kv3.1b in the MNTB is influenced by $30 \mathrm{~min}$ of acoustic stimulation with either lowfrequency or high-frequency AM sounds (Strumbos et al., 2010). We have now demonstrated that rapid sensory-dependent modification of the Kv3.1b gradient is absent in Fmr1 ${ }^{-/-}$mice, suggesting that FMRP-dependent protein synthesis in the auditory brainstem plays a role in maintaining appropriate levels of intrinsic neuronal excitability in different acoustic environments. The study of auditory temporal processing is of particular relevance to human FXS, as the disease is characterized by both hyperreactivity to acoustic stimuli (Miller et al., 1999) and a fluctuating pattern of speech (Hanson et al., 1986). Relative to healthy control subjects, FXS patients show significantly greater activation in several brain regions, including the brainstem, during auditory temporal discrimination tasks (Hall et al., 2009). Indeed, it is likely that the attention and learning impairments observed in FXS patients are at least partly the result of aberrant auditory function, which would be expected to interfere significantly with language development and social interactions.

In both the AVCN and MNTB, Kv3.1b is primarily localized to presynaptic terminals and in spine-like structures immediately ad- jacent to postsynaptic membranes (Wang et al., 1998a; Elezgarai et al., 2003). Therefore, our findings raise the exciting possibility that FMRP mediates local protein translation of Kv3.1b specifically at points of synaptic contact. Intriguingly, the mRNA for the hyperpolarization-activated $\mathrm{K}^{+}$channel HCN2, which is highly expressed in both the MNTB and AVCN, has also been identified as a likely binding partner for FMRP (Brown et al., 2001; Koch et al., 2004). Mouse MNTB neurons exhibit hyperpolarization-activated $(h-)$ currents, which vary systematically across the tonotopic axis in a pattern similar to the Kv3.1b current, with highest levels in medial neurons (Leao et al., 2006). Also in common with the gradient in $\mathrm{Kv} 3.1 \mathrm{~b}$ current, this tonotopic gradient in $h$-current is absent in congenitally deaf mice, suggesting that its maintenance requires stimulus-driven synaptic input. Future studies will be required to determine whether the regulation of HCN channel tonotopicity by sensory experience requires FMRP. The very large size of the calyx of Held, which permits patch-clamp studies of presynaptic function (Forsythe, 1994; Wang and Kaczmarek, 1998; Ishikawa et al., 2003), provides a unique opportunity for future investigations of FMRP-dependent local protein synthesis at both presynaptic and postsynaptic element of synaptic terminals.

In addition to the auditory brainstem, Kv3.1b is a key determinant of the activity patterns in a range of cell types including fast-spiking GABAergic interneurons throughout the cortex, thalamus, and hippocampus; pacemaker neurons in the suprachiasmatic nucleus; and Purkinje and granule cells in the cerebellum (Perney et al., 1992; Weiser et al., 1995; Rudy and McBain, 2001; Ozaita et al., 2002; Baranauskas et al., 2003; Itri et al., 2005; Sacco et al., 2006). Therefore, the finding that FMRP interacts with $K v 3.1$ mRNA in synaptosomes raises the possibility that dysregulated Kv3.1b translation in a variety of brain regions is a common etiology for many of the symptoms of human FXS. Indeed, there is a striking correspondence between the unique constellation of symptoms observed in FXS and the functions of the cell types that require Kv3.1b for high-frequency firing. For instance, dysregulation of Kv3.1b in fast-spiking GABAergic interneurons, where the subunit is nearly ubiquitous (Perney et al., 1992; Weiser et al., 1995), would be predicted to result in an imbalance between inhibition and excitation in thalamocortical networks, which is a major cause of seizures (McCormick and Contreras, 2001). FXS humans show increased susceptibility to epileptic seizures, with an incidence of $>20 \%$ in human FXS children (Musumeci et al., 1999). Similarly, Fmr1 ${ }^{-/-}$mice experience often-fatal audiogenic seizures in response to $60 \mathrm{~s}$ of exposure to very loud $(115 \mathrm{~dB})$ auditory stimuli (Chen and Toth, 2001). As a second example, recent studies have shown that the daily fluctuation in Kv3.1b protein levels over the $24 \mathrm{~h}$ light/dark cycle is required for circadian neural activity in the pacemaker cells of the suprachiasmatic nucleus (Itri et al., 2005). Dysregulation of Kv3.1b protein synthesis would thus be expected to result in circadian arrhythmicity. Consistent with this observation, double knock-out mice lacking both Fmr1 and its homolog Fxr2 are completely arrhythmic when maintained in normal light/ 
dark cycles (Zhang et al., 2008). Future studies will be required to determine whether these, and other, known phenotypes of $\mathrm{Fmrl}^{-1-}$ mice can be attributed to FMRP-dependent regulation of Kv3.1b translation.

\section{References}

Ashley CT Jr, Wilkinson KD, Reines D, Warren ST (1993) FMR1 protein: conserved RNP family domains and selective RNA binding. Science 262:563-566.

Baranauskas G, Tkatch T, Nagata K, Yeh JZ, Surmeier DJ (2003) Kv3.4 subunits enhance the repolarizing efficiency of Kv3.1 channels in fast-spiking neurons. Nat Neurosci 6:258-266.

Barnes-Davies M, Forsythe ID (1995) Pre- and postsynaptic glutamate receptors at a giant excitatory synapse in rat auditory brainstem slices. J Physiol 488:387-406.

Bassell GJ, Warren ST (2008) Fragile X syndrome: loss of local mRNA regulation alters synaptic development and function. Neuron 60:201-214.

Brew HM, Forsythe ID (2005) Systematic variation of potassium current amplitudes across the tonotopic axis of the rat medial nucleus of the trapezoid body. Hear Res 206:116-132.

Brown MR, Sullivan PG, Geddes JW (2006) Synaptic mitochondria are more susceptible to $\mathrm{Ca} 2+$ overload than nonsynaptic mitochondria. J Biol Chem 281:11658-11668.

Brown V, Jin P, Ceman S, Darnell JC, O’Donnell WT, Tenenbaum SA, Jin X, Feng Y, Wilkinson KD, Keene JD, Darnell RB, Warren ST (2001) Microarray identification of FMRP-associated brain mRNAs and altered mRNA translational profiles in fragile X syndrome. Cell 107:477-487.

Chen L, Toth M (2001) Fragile X mice develop sensory hyperreactivity to auditory stimuli. Neuroscience 103:1043-1050.

Darnell JC, Jensen KB, Jin P, Brown V, Warren ST, Darnell RB (2001) Fragile X mental retardation protein targets $\mathrm{G}$ quartet mRNAs important for neuronal function. Cell 107:489-499.

Ehret G, Romand R, eds (1997) The central auditory system. New York: Oxford UP.

Elezgarai I, Díez J, Puente N, Azkue JJ, Benítez R, Bilbao A, Knöpfel T, Doñate-Oliver F, Grandes P (2003) Subcellular localization of the voltage-dependent potassium channel $\mathrm{Kv} 3.1 \mathrm{~b}$ in postnatal and adult rat medial nucleus of the trapezoid body. Neuroscience 118:889-898.

Forsythe ID (1994) Direct patch recording from identified presynaptic terminals mediating glutamatergic EPSCs in the rat CNS, in vitro. J Physiol 479:381-387.

Gan L, Kaczmarek LK (1998) When, where, and how much? Expression of the Kv3.1 potassium channel in high-frequency firing neurons. J Neurobiol 37:69-79.

Guinan JJ, Norris BE, Guinan SS (1972) Single auditory units in the superior olivary complex: II: locations of unit categories and tonotopic organization. Int J Neurosci 4:147-166.

Hall SS, Walter E, Sherman E, Hoeft F, Reiss AL (2009) The neural basis of auditory temporal discrimination in girls with fragile X syndrome. J Neurodev Disord 1:91-99.

Hanson DM, Jackson AW 3rd, Hagerman RJ (1986) Speech disturbances (cluttering) in mildly impaired males with the Martin-Bell/fragile X syndrome. Am J Med Genet 23:195-206.

Iacoangeli A, Rozhdestvensky TS, Dolzhanskaya N, Tournier B, Schütt J, Brosius J, Denman RB, Khandjian EW, Kindler S, Tiedge H (2008) On
2 output cells

$>2$ output cells

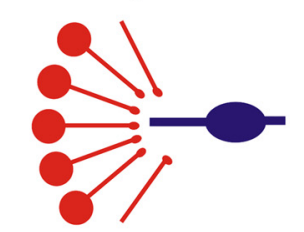

\section{b No Kv3.1 gradient $(0.2 \mu \mathrm{s})$}

Number of output cells

1251030

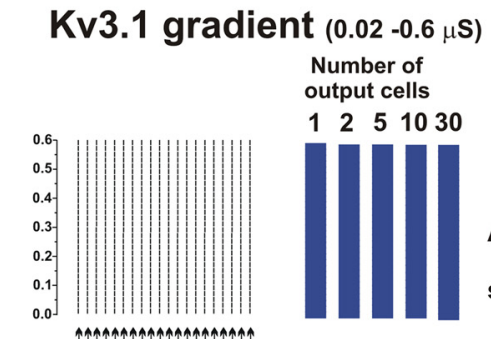

Number of output cells

1251030

$200 \mathrm{~Hz}$ stimulus

1251030

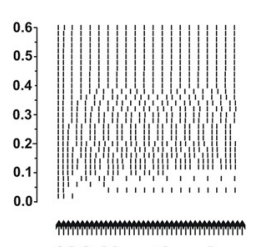

1251030

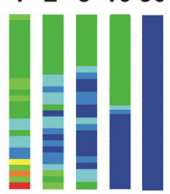

Adjusted

vector

strength

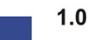

0.875
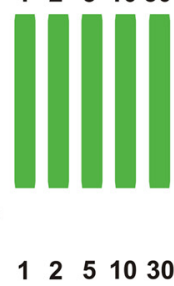

$400 \mathrm{~Hz}$ stimulus
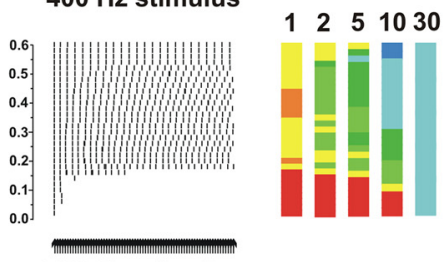

$700 \mathrm{~Hz}$ stimulus

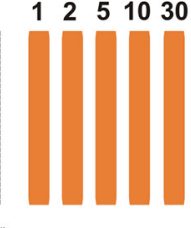

ductance may be required for accurate ensemble encoding of sound stimuli. a, Numerical simulations using a previously developed computer model of MNTB neurons illustrate the inherent advantage for auditory processing when a range of Kv3.1 conductances are present across the tonotopic axis. Model MNTB neurons (output neurons, red) are 作 , eurons, blue]. $\boldsymbol{b}$, Two sets of 30 neurons are shown, representing either uniform levels of Kv3.1 conductance ( $0.2 \mu$; ; left) or Coss the tonotopic axis (0.02-0.6 5 ; right) These model neurons were stimulated for 100 ms at 200, 400, or (a) 列 ern of firing in the group of neurons with fixed levels of Kv3.1 conductance, these two stimuli produce very different patterns of activity across the tonotopic axis when a gradient is present (right). With a gradient, the integrated phase vector improves as the number of cells contributing to encoding increases, whereas with uniform Kv3.1 levels it does not.

BC1 RNA and the fragile X mental retardation protein. Proc Natl Acad Sci U S A 105:734-739.

Ishikawa T, Nakamura Y, Saitoh N, Li WB, Iwasaki S, Takahashi T (2003) Distinct roles of Kv1 and Kv3 potassium channels at the calyx of Held presynaptic terminal. J Neurosci 23:10445-10453.

Itri JN, Michel S, Vansteensel MJ, Meijer JH, Colwell CS (2005) Fast delayed rectifier potassium current is required for circadian neural activity. Nat Neurosci 8:650-656.

Joris PX, Yin TC (1998) Envelope coding in the lateral superior olive. III. Comparison with afferent pathways. J Neurophysiol 79:253-269.

Kaczmarek LK, Bhattacharjee A, Desai R, Gan L, Song P, von Hehn CA, Whim MD, Yang B (2005) Regulation of the timing of MNTB neurons by short-term and long-term modulation of potassium channels. Hear Res 206:133-145.

Kadner A, Berrebi AS (2008) Encoding of temporal features of auditory stimuli in the medial nucleus of the trapezoid body and superior paraolivary nucleus of the rat. Neuroscience 151:868-887.

Kanemasa T, Gan L, Perney TM, Wang LY, Kaczmarek LK (1995) Electro- 
physiological and pharmacological characterization of a mammalian Shaw channel expressed in NIH 3T3 fibroblasts. J Neurophysiol 74:207-217.

Koch U, Braun M, Kapfer C, Grothe B (2004) Distribution of HCN1 and HCN2 in rat auditory brainstem nuclei. Eur J Neurosci 20:79-91.

Kopp-Scheinpflug C, Lippe WR, Dörrscheidt GJ, Rübsamen R (2003) The medial nucleus of the trapezoid body in the gerbil is more than a relay: comparison of pre- and postsynaptic activity. J Assoc Res Otolaryngol $4: 1-23$.

Kopp-Scheinpflug C, Tolnai S, Malmierca MS, Rübsamen R (2008) The medial nucleus of the trapezoid body: comparative physiology. Neuroscience 154:160-170.

Laggerbauer B, Ostareck D, Keidel EM, Ostareck-Lederer A, Fischer U (2001) Evidence that fragile $\mathrm{X}$ mental retardation protein is a negative regulator of translation. Hum Mol Genet 10:329-338.

Leao RN, Sun H, Svahn K, Berntson A, Youssoufian M, Paolini AG, Fyffe RE, Walmsley B (2006) Topographic organization in the auditory brainstem of juvenile mice is disrupted in congenital deafness. J Physiol 571:563-578.

Li W, Kaczmarek LK, Perney TM (2001a) Localization of two highthreshold potassium channel subunits in the rat central auditory system. J Comp Neurol 437:196-218.

Li Z, Zhang Y, Ku L, Wilkinson KD, Warren ST, Feng Y (2001b) The fragile $\mathrm{X}$ mental retardation protein inhibits translation via interacting with mRNA. Nucleic Acids Res 29:2276-2283.

Lu R, Wang H, Liang Z, Ku L, O'donnell WT, Li W, Warren ST, Feng Y (2004) The fragile $X$ protein controls microtubule-associated protein $1 \mathrm{~B}$ translation and microtubule stability in brain neuron development. Proc Natl Acad Sci U S A 101:15201-15206.

Macica CM, von Hehn CA, Wang LY, Ho CS, Yokoyama S, Joho RH, Kaczmarek LK (2003) Modulation of the kv3.1b potassium channel isoform adjusts the fidelity of the firing pattern of auditory neurons. J Neurosci 23:1133-1141.

McCormick DA, Contreras D (2001) On the cellular and network bases of epileptic seizures. Annu Rev Physiol 63:815-846.

Miller LJ, McIntosh DN, McGrath J, Shyu V, Lampe M, Taylor AK, Tassone F, Neitzel K, Stackhouse T, Hagerman RJ (1999) Electrodermal responses to sensory stimuli in individuals with fragile $\mathrm{X}$ syndrome: a preliminary report. Am J Med Genet 83:268-279.

Muddashetty RS, Kelić S, Gross C, Xu M, Bassell GJ (2007) Dysregulated metabotropic glutamate receptor-dependent translation of AMPA receptor and postsynaptic density-95 mRNAs at synapses in a mouse model of fragile X syndrome. J Neurosci 27:5338-5348.

Musumeci SA, Hagerman RJ, Ferri R, Bosco P, Dalla Bernardina B, Tassinari CA, De Sarro GB, Elia M (1999) Epilepsy and EEG findings in males with fragile X syndrome. Epilepsia 40:1092-1099.

Oertel D (1997) Encoding of timing in the brain stem auditory nuclei of vertebrates. Neuron 19:959-962.

Ozaita A, Martone ME, Ellisman MH, Rudy B (2002) Differential subcellular localization of the two alternatively spliced isoforms of the Kv3.1 potassium channel subunit in brain. J Neurophysiol 88:394-408.

Perney TM, Marshall J, Martin KA, Hockfield S, Kaczmarek LK (1992) Expression of the mRNAs for the Kv3.1 potassium channel gene in the adult and developing rat brain. J Neurophysiol 68:756-766.
Rudy B, McBain CJ (2001) Kv3 channels: voltage-gated K+ channels designed for high-frequency repetitive firing. Trends Neurosci 24:517-526.

Sacco T, De Luca A, Tempia F (2006) Properties and expression of Kv3 channels in cerebellar Purkinje cells. Mol Cell Neurosci 33:170-179.

Sommer I, Lingenhöhl K, Friauf E (1993) Principal cells of the rat medial nucleus of the trapezoid body: an intracellular in vivo study of their physiology and morphology. Exp Brain Res 95:223-239.

Song P, Yang Y, Barnes-Davies M, Bhattacharjee A, Hamann M, Forsythe ID Oliver DL, Kaczmarek LK (2005) Acoustic environment determines phosphorylation state of the Kv3.1 potassium channel in auditory neurons. Nat Neurosci 8:1335-1342.

Stefani G, Fraser CE, Darnell JC, Darnell RB (2004) Fragile X mental retardation protein is associated with translating polyribosomes in neuronal cells. J Neurosci 24:7272-7276.

Strumbos JG, Polley DB, Kaczmarek LK (2010) Specific and rapid effects of acoustic stimulation on the tonotopic distribution of Kv3.1b potassium channels in the adult rat. Neuroscience 167:567-572.

Taschenberger H, von Gersdorff H (2000) Fine-tuning an auditory synapse for speed and fidelity: developmental changes in presynaptic waveform, EPSC kinetics, and synaptic plasticity. J Neurosci 20:9162-9173.

Trussell LO (1999) Synaptic mechanisms for coding timing in auditory neurons. Annu Rev Physiol 61:477-496.

von Hehn CA, Bhattacharjee A, Kaczmarek LK (2004) Loss of Kv3.1 tonotopicity and alterations in cAMP response element-binding protein signaling in central auditory neurons of hearing impaired mice. J Neurosci 24:1936-1940.

Wang LY, Kaczmarek LK (1998) High-frequency firing helps replenish the readily releasable pool of synaptic vesicles. Nature 394:384-388.

Wang LY, Gan L, Perney TM, Schwartz I, Kaczmarek LK (1998a) Activation of Kv3.1 channels in neuronal spine-like structures may induce local potassium ion depletion. Proc Natl Acad Sci U S A 95:1882-1887.

Wang LY, Gan L, Forsythe ID, Kaczmarek LK (1998b) Contribution of the Kv3.1 potassium channel to high-frequency firing in mouse auditory neurones. J Physiol 509:183-194.

Weiser M, Bueno E, Sekirnjak C, Martone ME, Baker H, Hillman D, Chen S, Thornhill W, Ellisman M, Rudy B (1995) The potassium channel subunit KV3.1b is localized to somatic and axonal membranes of specific populations of CNS neurons. J Neurosci 15:4298-4314.

Whim MD, Kaczmarek LK (1998) Heterologous expression of the Kv3.1 potassium channel eliminates spike broadening and the induction of a depolarizing afterpotential in the peptidergic bag cell neurons. J Neurosci 18:9171-9180.

Yang B, Desai R, Kaczmarek LK (2007) Slack and Slick K(Na) channels regulate the accuracy of timing of auditory neurons. J Neurosci 27:2617-2627.

Zalfa F, Giorgi M, Primerano B, Moro A, Di Penta A, Reis S, Oostra B, Bagni C (2003) The fragile X syndrome protein FMRP associates with BC1 RNA and regulates the translation of specific mRNAs at synapses. Cell 112:317-327.

Zhang J, Fang Z, Jud C, Vansteensel MJ, Kaasik K, Lee CC, Albrecht U, Tamanini F, Meijer JH, Oostra BA, Nelson DL (2008) Fragile X-related proteins regulate mammalian circadian behavioral rhythms. Am J Hum Genet 83:43-52. 